\title{
Notas sobre la creación y realización del Derecho constitucional en la Argentina
}

\author{
Por Raúl Gustavo Ferreyra \\ “Qu'est-ce qu'un homme révolté ? Un homme qui dit non” \\ Albert Camus. L'Homme révolté, Paris, CEuvres, Gallimard, 2013, p. 854.
}

\section{I}

La existencia con vida y cognición de los individuos se justifica, racionalmente, si se realiza en una sociedad organizada y abierta. La armonía y el equilibrio comunitario pueden ser alcanzados en paz: regulación de la violencia por intermedio del Derecho. Alcanzada la paz, la desigualdad creciente e injusta se presenta como un flagelo con capacidad suficiente para afectarla.

La constitución del Estado se presenta como la pieza más celebrada ideada por el Derecho para disciplinar la administración de la fuerza estatal: una lengua para la paz. La fuerza sin regulación del Estado constituye la negación intolerable y la versión deshumanizada e irracional del Derecho. Del mismo modo que el lenguaje se rige por la gramática y la arquitectura por el espacio, el empleo de la fuerza del Estado se debe regir por el Derecho. Así, el Derecho, se yergue como la razón de la determinación y regulación de la fuerza del Estado. Quizá dicho de manera conmovedora, con más emoción que razón, la constitución de un Estado debería constituir la "escritura laica" de la ciudadanía que integra un pueblo, en un momento histórico determinado y también dentro de un territorio en el que sus poderes pueden ejercer, razonablemente, la soberanía.

II

La Argentina dispone para su ordenación jurídica de un "sistema constitucional federal"; su texto originario es de 1853 y fue reformado en 1860, 1866, 1898, 1957 y 1994. Está última reforma ha sido muy intensa porque aumentó la cantidad de normas constitucionales y estableció la jerarquía constitucional del Derecho 
internacional de los Derechos humanos (DIDH) como se determina en el artículo 75, inciso $22^{\circ 1}$.

Con la colección de esta descripción propongo que se vaya, ahora, por partes.

A) Las reglas constituyentes producidas en fuente nativa.

Tengo buenas razones para sostener que el Derecho constitucional federal en vigor de la Argentina está integrado por las siguientes disposiciones normativas: las enunciadas en el Preámbulo y las 129 reglas de naturaleza permanente -en realidad, son 130 porque hay una disposición normativa entre los arts. 14 y 15 a la que se ha denominado 14 bis, y que fue incluida por la reforma de 1957- y 17 de naturaleza transitoria que se enuncian en la Constitución federal de la Argentina, según la redacción que le ha conferido a su texto normativo y originario el poder constituyente ejercido en los años 1853/60, con las enmiendas de los años 1866, 1898 y 1957, y la reforma constitucional de 1994.

B) Las fuentes constituyentes provenientes de fuente extranjero.

1 Se dispuso en el art. 75, inc. 22: “... Corresponde al Congreso (...) inciso 22: Aprobar o desechar tratados concluidos con las demás naciones y con las organizaciones internacionales y los concordatos con la Santa Sede. Los tratados y concordatos tienen jerarquía superior a las leyes. La Declaración Americana de los Derechos y Deberes del Hombre; la Declaración Universal de Derechos Humanos; la Convención Americana sobre Derechos Humanos; el Pacto Internacional de Derechos Económicos, Sociales y Culturales; el Pacto Internacional de Derechos Civiles y Políticos y su Protocolo Facultativo; la Convención sobre la Prevención y la Sanción del Delito de Genocidio; la Convención Internacional sobre la Eliminación de todas las Formas de Discriminación Racial; la Convención sobre la Eliminación de todas las Formas de Discriminación contra la Mujer; la Convención contra la Tortura y otros Tratos o Penas Crueles, Inhumanos o Degradantes; la Convención sobre los Derechos del Niño; en las condiciones de su vigencia, tienen jerarquía constitucional, no derogan artículo alguno de la primera parte de esta Constitución y deben entenderse complementarios de los derechos y garantías por ella reconocidos. Sólo podrán ser denunciados, en su caso, por el Poder Ejecutivo nacional, previa aprobación de las dos terceras partes de la totalidad de los miembros de cada Cámara. Los demás tratados y convenciones sobre derechos humanos, luego de ser aprobados por el Congreso, requerirán del voto de las dos terceras partes de la totalidad de los miembros de cada Cámara para gozar de la jerarquía constitucional". A su vez, la ley 24.820 - publicada en el BO del 29/5/1997- otorgó jerarquía constitucional a la Convención Interamericana sobre Desaparición Forzada de Personas, aprobada por la XXIV Asamblea General de la OEA, en los términos del art. 75, inc. 22, de la Constitución federal. Por su parte, la ley 25778, publicada en el BO el 3/9/2003, otorgó jerarquía constitucional a la Convención sobre la Imprescriptibilidad de los Crímenes de Guerra y de los Crímenes de Lesa Humanidad, adoptada por la Asamblea General de la ONU el 26/11/1998 y aprobada por ley 24.584. Por su parte, la ley 27.044 publicada en el $\mathrm{BO}$ del 22/12/2014 dispuso otorgar jerarquía constitucional en los términos del art. 75, inc. 22 de la Constitución Nacional, a la Convención sobre los Derechos de las Personas con Discapacidad (ONU). En consecuencia, hoy son 14 los instrumentos del Derecho Internacional de los Derechos Humanos que gozan de jerarquía constitucional. 
Además, el sistema de la Constitucional federal es un modelo peculiar porque "congloba" entre sus elementos a reglas de raíz estatal junto a reglas provenientes de fuente supra estatal determinadas y en las condiciones de su propia vigencia. El Derecho internacional de los derechos humanos (DIDH) cumple la función de vincular el mundo del Derecho. Y aunque siempre propone una estructura compleja de integración, su pretendida inferioridad no fue demarcada por el poder constituyente reformador en 1994. El mensaje prescriptivo contenido en el DIDH es, resueltamente, integrar. Por lo tanto, desintegrar, es decir, determinar normas de primer rango o segundo, no enseña nada porque se opone a la verdad.

Así, pues:

i. Todos los enunciados del Derecho constitucional de la Argentina (permanentes y transitorios) tienen la misma jerarquía normativa;

ii. Todos los enunciados del DIDH que gozan de jerarquía constitucional tienen idéntica jerarquía normativa;

iii. Los enunciados del Derecho constitucional y los enunciados del DIDH (descritos en el punto ii) tienen rango jurídico idéntico, aunque difieren en la fuente o raíz: unos son producidos por la Constitución federal de la Argentina y otros son validados por ella, le abren la puerta a su normatividad.

iv. Diferente raíz de producción y/o validación; igual estatura normativa. Aunque, ciertamente, el Estado mantiene determinados límites razonables de reserva.

El texto ordenado por el sistema de la Constitución federal de la Argentina se desenvuelve en dos contextos: (i) el de su "producción" y el de su (ii) realización. Producida la norma constitucional por el poder constituyente (fuente interna) o proveniente su normatividad de fuente supra estatal (externa) por la vía de la conglobación que autoriza el artículo 75, inciso 22, deberá sobrevenir su "acatamiento", es decir, un "contexto" de realización propia tanto por los ciudadanos como por los poderes constituidos del Estado. Juzgo que no se hace necesario discutir o discernir si existe o no existe una obligación de cumplir con el Derecho constituyente del Estado. Puesta la constitución en el mundo en el marco de una sociedad de individuos igualmente libres y que aspiran a ser considerados como individuos socialmente iguales, cuya representación ha sido ejercida con libertad y deliberación por la autoridad constituyente y su composición fruto de elecciones auténticas, inevitablemente, desde la comprensión jurídica, deberá sobrevenir su acatamiento. 
No obstante, producida la norma constitucional no todo en el mundo jurídico será puro, listo y liso acatamiento. Para distinguir de la "mera aplicación o simple acatamiento", ahora, se llamará "realización propia" o "interpretación judicial” a la que cumplen los jueces cuando dictan sentencias.

La "realización” del Derecho constitucional, según el caso, se puede cumplir por el acatamiento o la interpretación judicial será siempre, pues, concreción o ejecución de Derecho creado. Concretamente: el Derecho constitucional del Estado lo produce el poder constituyente; su realización jamás podrá constituir el Derecho constituyente del Estado, salvo que se presenta alterar o deformar esta anatomía básica. Repárese en la ausencia de simplicidad de la aseveración, porque toda norma tiene un ámbito semántico, cuya certeza no es ni será aritmética. Hay un ejemplo muy didáctico; colocada la norma en el mundo se la puede comparar con barco. Así, necesitará de prácticos para llevar una ruta marcada por baqueanos en puerto y, luego, en mar libre dependerá para seguir el rumbo propio asignado por la autoridad constituyente de las tareas idóneas del capitán y de la tripulación de la embarcación (Radbruch, 1944: 148) ¡No cualquier rumbo! ¡Cualquier rumbo significará extraviar la semántica propuesta por la constitución y la negación de su naturaleza prescriptivo o su oscurecimiento!

\section{II. bis Entre acto}

Hay una cuestión excepcional que no se trata aquí en extensión y se remite en homenaje a la brevedad (Ferreyra, S/A: 269); en efecto, ciertas cuestiones no se encuentran redactadas en la Constitución federal. En este tipo de situaciones, ocasionales y contadas con los dedos de una mano, los jueces de la Corte Suprema de Justicia de la República (en adelante: CS) podrían superar la "laguna" del Derecho constitucional por intermedio de una sentencia que se pronuncie por unanimidad. Contrariamente, además, compútese, que, hay sentencias de la CS que no colman lagunas, vacían el texto constitucional. Sin embargo, pese a la referencia hecha al comienzo de párrafo, al encontrarse ligadas sentencias de la CS, se remite muy brevemente al parágrafo Quinto de la sección IV.

\section{III}

La Argentina, desde 1853 ha institucionalizado un Poder Judicial en el que la resolución de las cuestiones o disputas se suscita solamente por y en una "causa". Significa que la "sentencia" que decide dentro de una causa judicial debe ser acatada obligatoriamente por las partes intervinientes en el concreto y determinado proceso y conflicto judicial. La autoridad de la "sentencia" rige dentro de la causa judicial en la que fue resuelta por el magistrado. Y nada más, como regla general.

Dentro del sistema ordenado por la Constitución federal no se vislumbra ninguna regla o principio expreso que determine la obligatoriedad de las sentencias judiciales 
para personas que no han intervenido y que se encuentran fuera del proceso judicial en el que cumplió su dictado. No hay referencias constitucionales para postular la obligatoriedad de las sentencias fuera del proceso de su dictado ni respecto de las pronunciadas por los jueces inferiores ni respecto de las pronunciadas por los jueces de la CS. Decir que las sentencias judiciales de la CS cotizan en cualquier proceso o cualquier jurisdicción por fuera del proceso de su dictado, se acerca a una aseveración más cerca de la magia o de los buenos deseos sobre la marcha de las instituciones republicanas que de un predicado que goce de comprobación en la letra propia del sistema de la Constitución federal.

\section{IV}

La CS dictó su primera sentencia en octubre de 1863. Desde entonces este órgano ha intentado dilucidar la filiación o los alcances de la obligatoriedad de sus sentencias. La doctrina judicial de la CS ha tomado diferentes rumbos, tanto en el siglo XIX, como en el XX y también en el XXI. No podía ser de otro modo, porque, repito: no hay modulación constitucional respecto de la cotización de los propios fallos o sentencias que pronuncia el Más Alto Tribunal de Justicia de la República.

La doctrina judicial -la palabra de la CS sobre la valía o cotización jurídica de sus fallos- nunca ha sido uniforme y sobre todo, ha sido un itinerario errático. Porque, en rigor, se trata de un descubrimiento de identidad muy complejo: el sistema de la Constitución federal guarda silencio y para formular una aseveración sobre la materia se requiere instalar en la lengua de la ley fundamental una escritura que no existe en sus entrañas. Esto es: tanto las resoluciones judiciales dictadas por los jueces en sus causas, como las pronunciadas por los jueces de la CS, repito, son obligatorias y de cumplimiento inaplazables para todas las partes del proceso. Pese a ello, la autoridad de la resolución judicial, aunque se tratare de la doctrina judicial de la CS, no es obligatoria de modo vertical, esto es: para el resto de las causas que tramitan en diversos tribunales del Estado.

En el futuro, cuando se decida reformar el sistema de la Constitución federal, sería interesante discutir, si acaso, la obligatoriedad del precedente de la CS debería ser o no debería ser coactiva en todas las causas semejantes que se disciernan en el Estado, a condición de unanimidad o panorama semejante. Varios elementos juegan a favor de repensar la obligatoriedad de los sentencias de la CS: la economía procesal y la igualdad ante el Derecho que se podría conmover por la existencia de tratamiento diferencial en semejantes condiciones. Mientras tanto, hoy, la autoridad institucional de dichas sentencias de la CS puede ser removida -por un juez inferior, en otra causa judicial- siempre que se brinde una postura nítida, inequívoca y concluyente sobre la doctrina que funda el apartamiento del legajo de la doctrina del Más Alto Tribunal de Justicia de la República. Téngase presente, además, que esa propia doctrina sobre la 
obligatoriedad de las sentencias de la CS la legisla la propia CS sin indicación expresa en la letra constitucional. Aunque no se encuentran obligados constitucionalmente, los jueces inferiores pueden seguir la doctrina judicial determinada por la CS; desde luego, dicha doctrina de la CS cambia con el tiempo, porque, dicho tribunal en su integración con jueces, al igual que toda la vida humana, descansa en la dialéctica del tiempo y sus procesos de cambio. Más directamente: la doctrina de la CS puede cambiar y de hecho cambia, institucionalmente, con la integración de otros jueces. El lector, además, se asombrará, si leyese que un juez de la CS mantuvo una posición en contra de la prosecución del juicio y castigo de los sujetos criminales que pusieron en marcha el terrorismo de Estado en el siglo XX y otra de signo contrario en el siglo XXI; no es ninguna novela, porque ha sucedido en la historia judicial del Más Alto Tribunal de Justicia.

\section{Redondeo mis ideas}

Primero. Aunque la mayoría de los Estados disponen de una constitución escrita, en muchísimas ocasiones existe una notable disparidad entre el ámbito de lo normado por las prescripciones constitucionales y el ámbito del respectivo cumplimiento o realización de la aludida prescripción. La distorsión señalada, por lo general, obedece a incumplimientos de los servidores públicos, sujetos con fuerte vocación para no realizar las normas constituyentes de un Estado.

Segundo. El sistema de la Constitución federal no determina la obligatoriedad vertical de los fallos de la CS. Las decisiones de la CS pueden no ser acatadas por los jueces inferiores; naturalmente, a condición que estos entreguen razones decisivas, fundadas y justificantes para realizar dicho proceder institucional. Ergo, los jueces inferiores (cualquier juez) pueden apartarse de la doctrina judicial de la Corte, en las condiciones antedichas.

Tercero. La propia doctrina de la CS sobre la obligatoriedad de sus propios precedentes es una elaboración autorreferencial, que, como construcción de esta prosapia reserva para sí la cualidad inherente de la contradicción. La contradicción emergente de una predicado autorreferencial lo sostiene la lógica; el autor de estas letras, simplemente, lo pone en evidencia.

Cuarto. Existen cánones indisputables en materia de realización del Derecho constitucional. La realización de los derechos y deberes fundamentales, cuando son examinadas por los jueces de la CS, debe serlo bajo la consigna de la "no regresividad". Nunca un juez de la CS debe devaluar o pulverizar el contenido de un derecho fundamental; si así lo hiciese se vulnerarían las reglas del Derecho internacional de los Derechos Humanos que gozan de jerarquía constitucional. Los derechos fundamentales son una conquista del denominado constitucional global que se instauró, en normas positivas, con propiedad y solvencia, luego de la 2a Guerra 
Mundial. La restricción de un derecho fundamental, que impida la prosecución de su desarrollo progresivo o peor todavía el regreso a una situación del pasado, siempre, llevará sobre sí la mácula de una indefendible inconstitucionalidad y, ahora, también, la violación de compromisos internacionales asumidos por la Argentina en los términos prescritos por el artículo 75 , inciso $22^{\circ}$.

Cuando los jueces de la CS analizan cuestiones relacionadas con los poderes constituidos del Estado, específicamente, atribuciones de los mismos, deben actuar con extremada cautela y prudencia, porque la regla de la interpretación judicial en este ámbito es la competencia restringida que tiene cada poder instituido por la constitución. Se ha indicado que en el ámbito de los derechos fundamentales el canon es la fulminación de la regresividad que los lesione o de cualquier forma intente su devaluación o aniquilamiento; en cambio, en materia de atribuciones de los poderes, la regla es un escrutinio riguroso dirigido a actuar, siempre, en el sentido que se trata de competencias restringidas.

El Derecho constitucional es, por regla, objeto de interpretación. La interpretación judicial, en el marco de una sociedad abierta, es una de las formas que asume la realización del Derecho constitucional. Ciertamente, con el transcurso del tiempo esa misma sociedad desarrolla nuevos puntos de vista. Significan un progreso decisivo y definitivo, en el marco de la deliberación democrática, que refuerzan los derechos fundamentales existentes y deja constancia o estímulo hacia nuevas conquistas. Aunque es una regla de nuestra existencia como humanos que todo lo que nace perecerá, en el ámbito de las idealidades jurídicas ya concretadas queda prohibida la regresión al pasado, el retorno a la impunidad abyecta.

Quinto. Las estrategias interpretativas desarrolladas por la CS han demostrado tener aptitud para poner en evidencia que el producto de la actividad también, y al mismo tiempo, fue capaz de constituir una fuente de producción normativa del sistema de la Constitución federal, debido a la expansión generalizada de la coactividad que emanaba de tales prescripciones resolutivas. Del propio repertorio de decisiones judiciales de la CS se puede citar una variada gama de fallos que tienen una ligazón importante, desde el punto de vista empírico, con las estipulaciones formuladas. Así, en una brevísima lista de ejemplos, puede advertirse el poder creativo de Derecho constitucional, por parte del Más Alto Tribunal de Justicia de la Nación. Simplemente, a título de ejemplo: a) el otorgamiento de ciudadanía constitucional a la acción de amparo, en el caso "Siri" (1957); b) el reconocimiento de jerarquía supralegal de los tratados, en el caso "Ekmekdjian c/Sofovich" ${ }^{2}$ c) las bases para la elaboración de la doctrina de arbitrariedad de sentencias, en el caso "Rey c/Rocha";

2 CSJN, Fallos: 315: 1492 (1992).

3 CSJN, Fallos: 112:384 (1909). 
d) el acceso a la justicia y mención sobre la regulación de las acciones de clase, en la causa "Halabi"; e) enjuiciamiento de crímenes de lesa humanidad, en el caso "Simón" (2005) : posiblemente, el fallo más relevante, si existiese tal mención, en toda la historia política del Más Alto Tribunal de Justicia de la República. Todas estas interpretaciones constituyen actos de lealtad constitucional. El intérprete genera una nueva regulación normativa que, antes de su decisión, no existía descrita como el intérprete (creador, no ya realizador) ahora regiamente dispone.

Probablemente, el peor acto jurídico de la CS en toda su historia no fue un fallo judicial. Las fuerzas de la soledad en el Derecho, la peligrosa vía de la incomunicación, concretamente el dominio de la irracionalidad, tiene una radiografía específica: la "Acordada de la CS" pronunciada el 10 de septiembre de 1930, suscrita por cuatro jueces de la CS y el procurador general, quienes abjuraron del Derecho constitucional, sin contemplación. ${ }^{6}$ Recientemente, el 3 de mayo de 2017, en el caso "Muiña", resuelto por 3 jueces de la CS que conformaron la mayoría y sin considerar, razonablemente, la naturaleza imperativa del DIDH que goza de jerarquía constitucional y semejante naturaleza imperativa de las normas legales vigentes y efectivamente aplicables, decidieron beneficiar, sin justificación jurídica, en el cómputo de la prisión (a razón de 2 días por cada 1 efectivo) a un sujeto enjuiciado por la comisión de crímenes de lesa humanidad; 2 jueces votaron en minoría. La decisión judicial provocó que millones de ciudadanos repudiaran la impunidad congénita dispuesta por 3 jueces en la sentencia; movilizaciones que se produjeron al este, al oeste, al sur y al norte del país; nunca, en toda la historia de la Argentina sucedió una movilización ciudadana igual, espontánea e incremental, en repudio a un fallo de la CS. Paralelamente, jueces inferiores de todo el país, en sus pronunciamientos no aplicaron la doctrina del caso "Muiña" porque ella supone el incumplimiento por parte del Estado argentino de las obligaciones asumidas, en todos sus poderes, con hegemonía suficiente, sobre la política de investigar, enjuiciar y sancionar los crímenes de lesa humanidad cometidos a partir del 24/3/1976 por el Estado terrorista y cuya consumación, en muchos casos todavía, perdura por la naturaleza de los delitos. La comunidad argentina, al aceptar los instrumentos internacionales, no puede desmerecer o devaluar por intermedio de sus poderes constituidos ni las pretensiones punitivas ni articular mecanismos de amnistía, perdón o cualquier otra forma de cumplimiento privilegiada y diferenciada de la detención o

4 CSJN, "Halabi, Ernesto", (2009).

$5 \mathrm{~V}$. in re "Simón, Julio et al", CSJN, (2005).

6 El texto completo de la Acordada se encuentra recogido en CSJN, Fallos: 158:290. 
prisión. Casi por única vez en la historia de la Argentina el Congreso sancionó la ley $27.362^{7}$ con una velocidad superior a la luz y el Poder Ejecutivo la promulgó con idéntica rapidez.

Sexto. El sistema de la Constitución federal divide el mundo en dos: un ámbito jurídico y otro ámbito no jurídico.

Séptimo. El ámbito jurídico se encuentra poblado de permisiones, obligaciones y prohibiciones, cuya última palabra, eventualmente, escalado el anticuado sistema jurisdiccional de la Argentina podría llegar a la CS. Si el Más Alto Tribunal se pronuncia en una causa, la sentencia valdrá para las partes (las personas físicas o ideales) que han intervenido en el juicio; dicha sentencia no es jurídicamente obligatoria para el resto de los ciudadanos que no participaron del citado juicio o pleito, quienes, hipotéticamente, podrían introducir otros argumentos en otros escenarios judiciales y antes otros jueces, quienes, podrían resolver el futurible litigio con desapego a la doctrina predeterminada por la CS.

Octavo. El otro ámbito es el mundo ajurídico, el sitio en el que el Derecho constitucional no llega y constituye el paraíso de la privacidad de cada ciudadano, cuyo dominio y fecundidad se encuentra reservado solamente a él.

Noveno. Las distinciones apuntadas y las descripciones desarrolladas sostienen, hasta cierto punto, las ilusiones sobre una sociedad abierta de los realizadores de la constitución en paz. El poder constituyente conduce y elabora la parición de las partituras laicas, la constitución; los servidores públicos, en especial los jueces de la CS, deben cumplir su interpretación judicial para el caso concreto y su validez, en principio, queda restringida al ámbito de dicho proceso judicial en que dictó la sentencia.

7 Artículo 1. De conformidad con lo previsto en la ley 27.156, el artículo 7o de la ley 24.390 derogada por ley 25.430- no es aplicable a conductas delictivas que encuadren en la categoría de delitos de lesa humanidad, genocidio o crímenes de guerra, según el derecho interno o internacional. Art. 2. El cómputo de las penas establecido en su oportunidad por el artículo $7^{\circ}$ de la ley $24.390-$ derogada por ley 25.430 - será aplicable solamente a aquellos casos en los que el condenado hubiere estado privado de su libertad en forma preventiva durante el período comprendido entre la entrada en vigencia y la derogación de aquella ley. Art. 3. Lo dispuesto por los artículos anteriores es la interpretación auténtica del artículo $7^{\circ}$ de la ley 24.390 -derogada por ley 25.430 - y será aplicable aún a las causas en trámite. 